\title{
EVENTOS NEOCENOZOICOS DE REORGANIZAÇÃO DE REDE DE DRENAGEM: UM PALEOVALE DO RIO DAS VELHAS (MINAS GERAIS, BRASIL) EM SEU MÉDIO CURSO?
}

\author{
ANTÔNIO PEREIRA MAGALHÃES JR.(1), LUIZ FERNANDO DE PAULA BARROS ${ }^{(2)}$, LUIS FELIPE \\ SOARES CHEREM ${ }^{(3)} \&$ ROBSON CLAYTON PINTO ${ }^{(4)}$
}

Resumo:

\begin{abstract}
O presente trabalho teve como objetivo apresentar e discutir indícios de processos de reorganização da rede de drenagem na média bacia do Rio das Velhas resultantes da reconfiguração de seu vale principal. Nesse sentido, diversos depósitos fluviais foram identificados, descritos e, alguns, datados por Luminescência Opticamente Estimulada (LOE). Os resultados sugerem que a descontextualização de um conjunto de depósitos fluviais em cotas superiores e topos de colinas e a existência de anomalias na organização da rede de drenagem nesse trecho seriam
\end{abstract} resultantes da mudança do traçado do canal principal do Rio das Velhas no Quaternário Superior.

Palavras-chave: Níveis deposicionais fluviais; Luminescência Opticamente Estimulada; Evolução de rede hidrográfica.

Abstract:

\begin{abstract}
Neocenozic events of drainage network reorganization: a paleovalley of the Velhas River (Minas Gerais, Brazil) in its middle course?

This paper aimed to present and discuss clues of reorganization processes of the drainage network in the middle Velhas River catchment resulting from the reconfiguration of its main valley. In this sense, several fluvial deposits were identified, described and, some, dated by Optically Stimulated Luminescence (OSL). The results suggest that the decontextualization of a set of fluvial deposits in higher elevations and tops of hills, as well as the existence of anomalies in the organization of the drainage network in this stretch would results of the change of the main channel of the Velhas River during the Late Quaternary.
\end{abstract}

Keywords: Fluvial depositional levels; Optically Stimulated Luminescence; Evolution of hydrographic network

\section{INTRODUCC̃̃O}

A investigação sobre a evolução das redes de drenagem fornece resultados únicos para uma melhor compreensão do relevo ao longo do tempo e em diferentes escalas. O rearranjo da rede de drenagem inclui processos de captura fluvial, desvio e decapitação, os quais podem ser significativos para a evolução da paisagem, alterações no fornecimento sedimentar e na distribuição de biótopos (BIsHOP 1995). No entanto, os determinantes envolvidos nesses processos não são óbvios, podendo incluir implicações climáticas, tectônicas, litoestruturais e de alteração do nível de base (James 1995; Mather 2000; Dumont et al. 2006; Benvenuti et al. 2008). Dessa forma, os eventos de reorganização da drenagem são elementos chave para o entendimento da evolução do relevo.

Com cerca de 640 mil km², a bacia do Rio São Francisco é a maior bacia hidrográfica inteiramente situada no território brasileiro e drena, majoritariamente, o Cráton homônimo, um domínio com relativa estabilidade tectônica desde o Neoproterozoico (TROMPETTE et al. 1992). Não obstante, diversos remanescentes de superfícies erosivas escalonadas foram identificados na região, além de alguns eixos de soerguimento e subsidência cenozóicos (KING 1956; VARAJão 1991; SiLVA 2009; VALADÃo 2009). As superfícies erosivas receberam diferentes nomenclaturas e sua gênese e geodinâmica são objeto de diferentes interpretações.

Valadão (2009) identificou nove capturas fluviais em afluentes do Rio São Francisco, em seu trecho no estado de Minas Gerais (sudeste do Brasil), relativas ao Plio-Pleistoceno, indicando processos geomorfológicos associados à origem e dinâmica dos registros das superfícies. Desse modo, nessa bacia hidrográfica, as dinâmicas de longo termo do relevo regional e da rede de drenagem apresentam interdependência e se retroalimentam no rearranjo da paisagem.

Em Minas Gerais, a porção centro-leste do cráton em questão é drenada pela bacia do Rio das Velhas, um dos maiores afluentes do Rio São

\footnotetext{
${ }^{(1)}$ Departamento de Geografia do Instituto de Geociências da Universidade Federal de Minas Gerais. Autor correspondente: antonio.magalhaes.ufmg@gmail.com (Antônio Pereira Magalhães Jr.);

${ }^{(2)}$ Departamento de Geografia do Instituto de Geociências da Universidade Federal de Minas Gerais;

${ }^{(3)}$ Instituto de Estudos Sócio-Ambientais da Universidade Federal de Goiás;

${ }^{(4)}$ Geógrafo e mestre em Geografia e Análise Ambiental.
} 
Francisco. $\mathrm{O}$ alto curso drena um relevo montanhoso, situado no domínio do Quadrilátero Ferrífero, o qual tem sido objeto de diversas pesquisas sobre a geomorfologia fluvial cenozoica nos últimos anos, seja em âmbito regional (BARROS \& MagalHÃes JR. 2018a;b; 2019), com foco no vale do Rio das Velhas (Magalhães JR. E SAADI, 1994; MAGAlHÃES JR. et al., 2011) ou nos seus afluentes (Valadão \& Silveira 1992; Bacellar et al. 2005; RAPOSO et al. 2008; LANA \& CASTRO 2010; Magalhães JR. et al. 2012; Barros \& Magalhães JR. 2012). Esses resultados têm corroborado a interdependência entre as dinâmicas do relevo regional e da rede hidrográfica, ilustrando a relevância da evolução neocenozoica dos cursos fluviais para a compreensão da morfogênese da paisagem.

Em seu médio trecho, a bacia do Rio das Velhas drena uma região de relevo cárstico desenvolvido sobre as rochas carbonáticas do Grupo Bambuí, conhecido como Carste de Lagoa Santa (Piló 1998). Na região cárstica de Lagoa Santa, Magalhães Jr. \& Saadi (1994) encontraram vestígios de depósitos fluviais a $750 \mathrm{~m}$ de altitude e os colocaram como os mais antigos do Rio das Velhas naquele trecho. Estes remanescentes seriam resultantes da dissecação pós Superfície SulAmericana de King (1956). A calha fluvial atual drena em cotas médias de $700 \mathrm{~m}$ de altitude. Os autores supracitados interpretaram que esse desnível foi gerado, possivelmente, por uma tectônica diferencial de blocos associada às reativações epirogenéticas do Escudo Brasileiro. Como consequência, o bloco que drena o substrato de rochas carbonáticas foi dissecado. Entretanto, na porção mais à montante desse trecho médio, não foram encontrados sedimentos em cotas superiores a $750 \mathrm{~m}$ de altitude, ou seja, registros fluviais que pudessem ser correlativos da Superfície SulAmericana.

Em trabalhos mais recentes, elaborados na bacia do Médio Rio das Velhas em trecho à jusante da área do estudo referido anteriormente, Pinto \& Magalhães Jr. (2006; 2009) descrevem a ocorrência de depósitos em cotas superiores em vales de afluentes que não ocorrem no vale principal. Além disso, em razão de suas dimensões e características sedimentares, os depósitos encontrados em vales de afluentes do Rio das Velhas (especificamente, dos ribeirões da Mata e Jequitibá) se mostraram incompatíveis com seu contexto atual, sugerindo sua formação por uma paleodrenagem de maior capacidade e competência.

O objetivo do presente trabalho é, nesse contexto, apresentar e discutir indícios de processos de reorganização da rede de drenagem na bacia do Médio Rio das Velhas resultantes da reconfiguração de seu vale principal. Partiu-se da hipótese que a descontextualização espacial de um conjunto de depósitos fluviais em relação à drenagem atual e a existência de anomalias na organização da rede de drenagem nesse trecho resultam da mudança do canal principal do Rio das Velhas. Nesse sentido, diversos depósitos fluviais foram mapeados, descritos e, alguns, datados por Luminescência Opticamente Estimulada (LOE). Por fim, os dados foram correlacionados à organização espacial dos elementos geomorfológicos e geológicos para a sustentação da hipótese inicial.

\section{A BACIA DO RIO DAS VELHAS}

O Rio das Velhas é o maior afluente em extensão do Rio São Francisco, um dos maiores e mais importantes rios brasileiros. A bacia hidrográfica do Rio das Velhas drena uma área de aproximadamente $29 \mathrm{mil} \mathrm{km}^{2}$ na porção central de Minas Gerais. O canal principal segue direção aproximada NW, paralelo à Serra do Espinhaço Meridional (divisor de águas leste da bacia - Fig. 1), e possui extensão total de cerca de $800 \mathrm{~km}$, com largura média de $40 \mathrm{~m}$.

Situada na bacia do Médio Rio das Velhas, a área investigada é delimitada, aproximadamente, pelos paralelos $19^{\circ} 10^{\prime} \mathrm{S}$ e $19^{\circ} 45^{\prime} \mathrm{S}$ e os meridianos $43^{\circ} 50 \mathrm{~W}$ e $44^{\circ} 15 \mathrm{~W}$ (Fig. 1). Os principais afluentes da margem esquerda do Rio das Velhas apresentam a direção principal entre leste e nordeste, exceto o Ribeirão da Mata, que drena para sudeste.

Parte da bacia do Médio Rio das Velhas drena sobre o Grupo Bambuí (rochas sedimentares e metassedimentares de origem marinha e de idade neoproterozoica). $\mathrm{Na}$ área mais à montante, afloram rochas do Embasamento Cristalino (granitos e gnaisses de idade arqueana). Os interflúvios regionais são a Serra do Espinhaço Meridional, a Leste, a Serra de Santa Helena, a Oeste, e as serras da borda sul do Quadrilátero Ferrífero, a Sul.

A morfologia da área é predominantemente suave, com colinas alongadas associadas ao relevo cárstico e profundos mantos de intemperismo. Cuestas típicas e pseudo-cuestas também podem ser observadas (Fig. 2). Com altitude média de 750 $\mathrm{m}$, elas separam o relevo rebaixado (entre $650 \mathrm{e}$ $700 \mathrm{~m}$ ) do entorno do Rio das Velhas e dos morros com altimetria entre 800 e $1.000 \mathrm{~m}$ de níveis remanescentes da Superfície de Aplanamento SulAmericana, conforme apresentado por Valadão (2009).

O contato do Cráton São Francisco com as faixas móveis marginais ocorre nos limites W e E por falhas de empurrão de alto ângulo. Ocorrem ainda falhas de gravidade, falhas de cavalgamento nos limites de sua borda ocidental e falhas de rasgamento (COSTA \& GROSSI SAD 1987). Estudos anteriores demonstraram também a ocorrência de reativações neotectônicas nas rochas do Grupo Bambuí atingindo a borda do Cráton Brasiliano do São Francisco (Uhlein \& PAIM 1989; Magalhães JR. \& SAADI 1994). King (1956) e Saadi (1995) consideraram que a depressão ocupada pelos rios Cipó e Velhas, no entorno da Serra do Espinhaço Meridional (borda leste do Cráton), corresponderia a um graben gerado por abatimento tectônico, resultando num deslocamento vertical de cerca de 300 a 400 m (SAADI 1995). A concepção neotectônica dos estudos regionais considera, geralmente, os eventos ocorridos durante $o$ Cenozóico, após a abertura do Atlântico Sul, ou seja, em um período de tempo iniciado há cerca de 
65 milhões de anos e que estende até a atualidade.

Nesse sentido, muitas das falhas presentes no interior do Grupo Bambuí foram potenciais focos de reativação no Meso-Cenozoico. Sobre as suas rochas o Rio das Velhas aprofunda o seu leito, esculpindo um vale sinuoso com vertentes íngremes. A alta sinuosidade dos cursos fluviais nesta área é condicionada pela existência de sistemas de falhas e fraturas que guiam o leito fluvial, formando "meandros encaixados".

A região apresenta clima tropical semi-úmido com regime sazonal de chuvas que se enquadra no tipo Aw de Koppen (Alvares et al., 2013). A estação chuvosa ocorre de outubro a março, enquanto a estação seca vai de abril a setembro. A temperatura média anual é de cerca de $21^{\circ} \mathrm{C}$ e os totais anuais de chuva entre $1.300-1.400 \mathrm{~mm}$. Em termos de formações vegetais, subsistem atualmente remanescentes de mata tropical do interior, especialmente as matas ciliares, e diversas fitofisionomias savânicas (CAMARGOS, 2005).

Apesar de o clima atual ter se estabelecido na região desde $\sim 5.000$ anos $\mathrm{BP}$, pequenas oscilações na precipitação entre $\sim 3.000$ anos BP e o presente foram observadas (PARIZZI et al. 1998), o que foi confirmado por Salgado-Labouriau et al. (1998) para outras áreas do Brasil Central. Diversos cenários paleobioclimáticos se sucederam na região ao longo do Quaternário Tardio, entretanto há grande escassez de dados anteriores a 50.000 anos BP (BARRos et al. 2011).

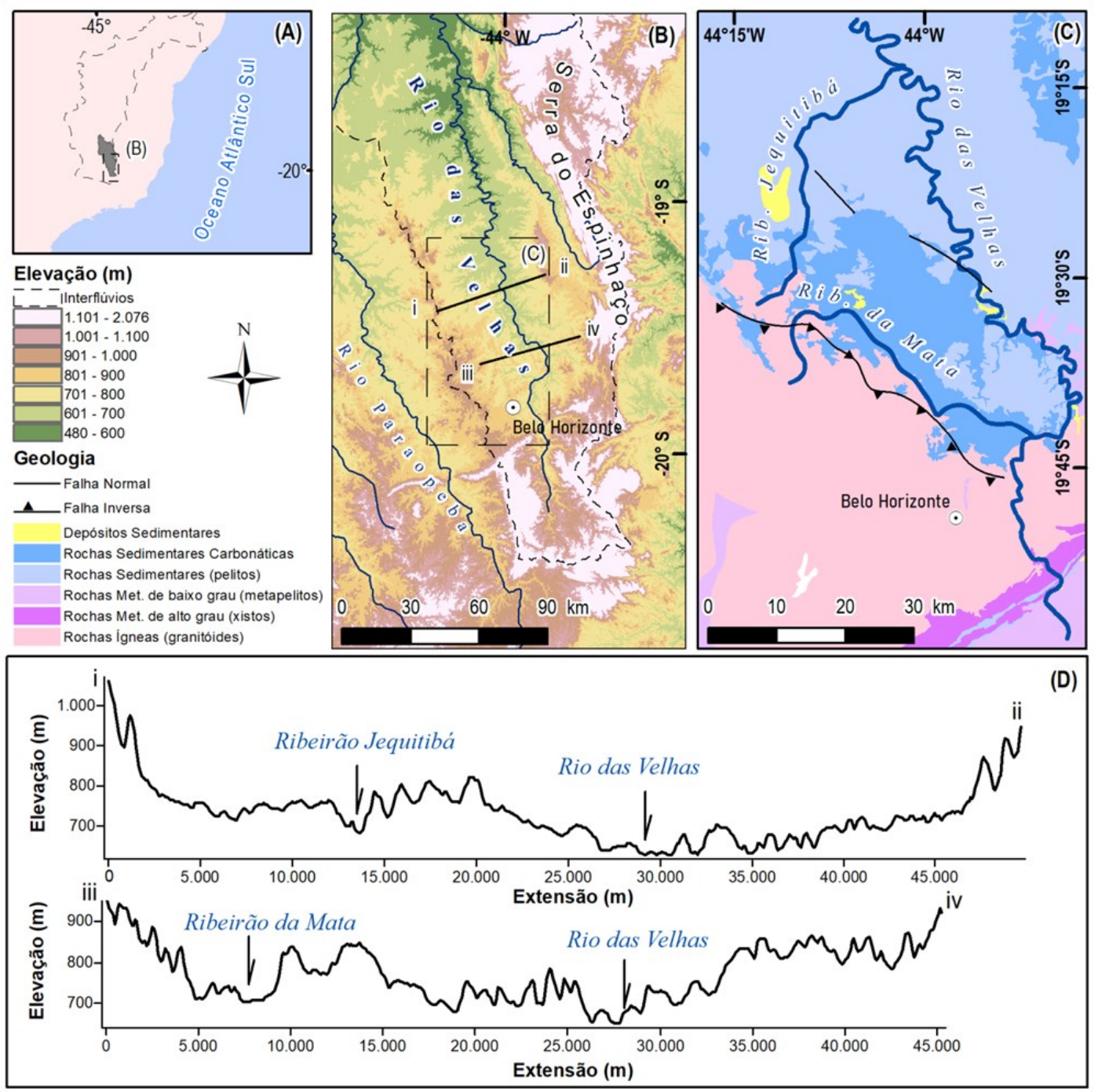

Fig. 1: Contextualização espacial e altimétrica do vale do Rio das Velhas A) Localização da bacia do Rio das Velhas em Minas Gerais; B) Mapa hipsométrico regional; C) Esboço geológico da região investigada; D) Perfis altimétricos transversais aos vales.

Fig. 1: Spatial and altimetric contextualization of the Rio das Velhas valley: A) Location of the Velhas River catchment in Minas Gerais; B) Regional hypsometric map; C) Geological sketch of the investigated region. 

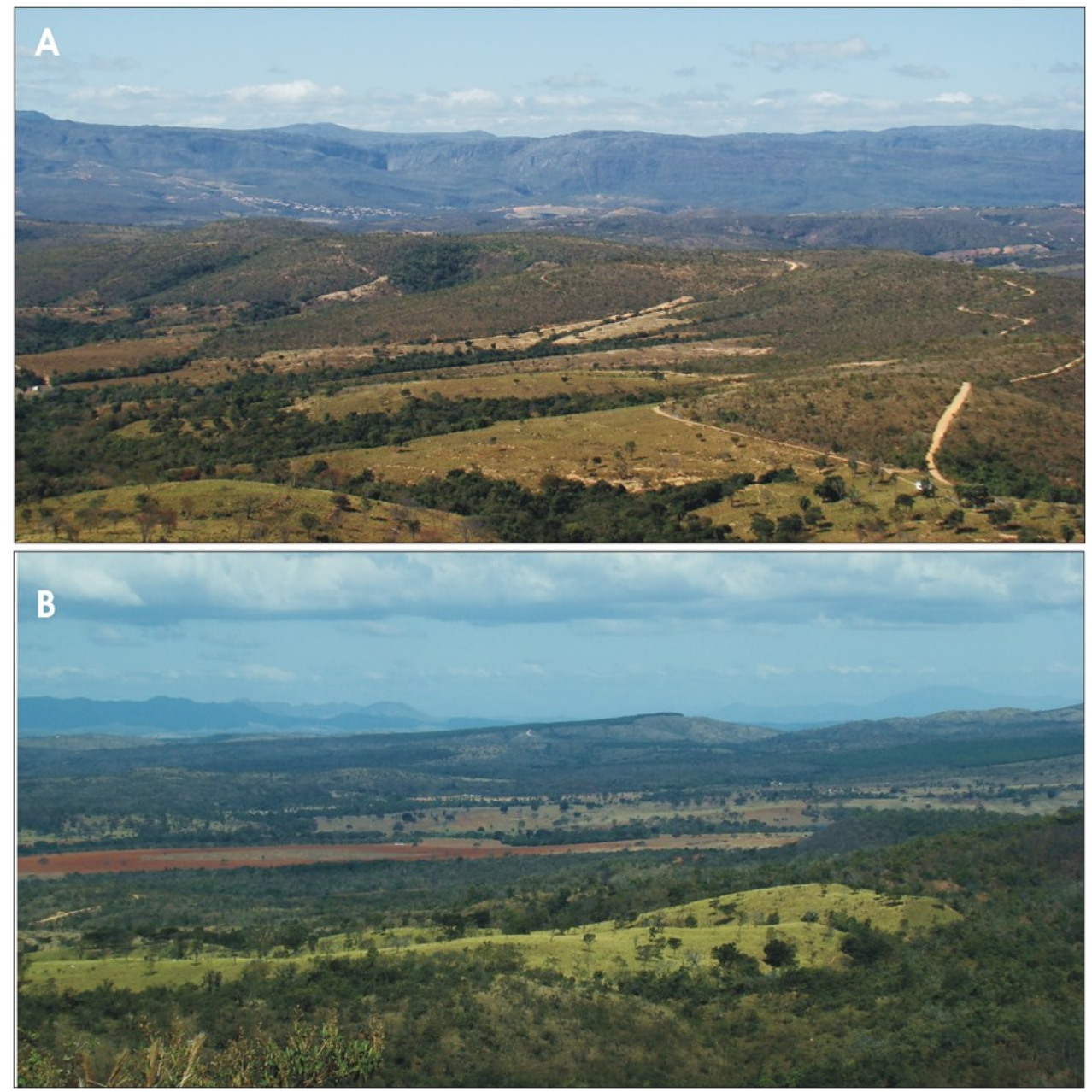

Fig. 2: Aspecto geral do relevo na região do médio Rio das Velhas, na porção mais próxima à foz do ribeirão Jequitibá: a) colinas e Serra do Espinhaço Meridional ao fundo; b) aspecto cuestiforme de alguns modelados. Fig. 2: General aspect of the relief in the region of the middle Velhas River, near the mouth of the Jequitibá Stream: a) hills and Serra do Espinhaço Meridional in the background; b) cuestiform aspect of some hills.

\section{MATERIAIS E MÉTODOS}

O presente trabalho foi motivado pela identificação de significativos registros deposicionais fluviais em topos de morros nas bacias dos ribeirões da Mata e Jequitibá, tendo em vista que tais registros são incompatíveis com a área de drenagem destes pequenos cursos d'água, afluentes da margem esquerda do médio Rio das Velhas. Nesse sentido, foram pesquisados os vales desses três cursos d'água, a fim de se investigar a recorrência espacial destes registros e levantar um maior número de sucessões deposicionais e outras evidências geomorfológicas que permitam atribuir tais depósitos a uma paleo-organização da drenagem.

Assim, a identificação e análise de sucessões sedimentares fluviais constituíram o primeiro passo para a reconstituição geomorfológica da evolução espaço-temporal da rede de drenagem e das condições sindeposicionais. A análise estratigráfica dos depósitos seguiu o modelo de análise de fácies de Miall (1999), observando-se sua organização (sequência), granulometria (argila, silte, areia ou cascalho), espessura e tipo de transição (gradual ou abrupta), além da presença ou ausência de estruturas sedimentares, matéria orgânica, cimentação por oxihidróxidos de ferro e bioturbação. Os clastos também foram descritos quanto ao seu tamanho médio, petrografia, arredondamento e tipo de matriz associada.

Do conjunto de registros sedimentares fluviais investigados na área, foram escolhidos cinco dentre os depósitos situados nos níveis altimetricamente mais elevados em cada vale para a amostragem de sedimentos para datação (Tab. 1). A datação por LOE foi baseada na coleta de amostras ao abrigo da luz, em exposições naturais ou em cortes. Foram utilizados sacos plásticos pretos e tubos de PVC (5 $\mathrm{cm}$ de diâmetro e $30 \mathrm{~cm}$ de comprimento). Estes foram inseridos horizontalmente por percussão, utilizando-se uma marreta de borracha para coletar amostras em camadas mais arenosas e mais próximas da base das sucessões aluviais. As 
amostras foram enviadas para o laboratório Datação, Comércio e Prestação de Serviços (em São Paulo, Brasil), onde foram preparadas e analisadas pelo método MAR (multiple-aliquotregenerativedose) para a extração das idades absolutas via LOE em grãos de quartzo. Embora existam métodos mais precisos, segundo Jain et al. (2004), o método MAR é suficiente para se obter idades confiáveis de sedimentos do Holoceno Inicial e Médio e do Pleistoceno Tardio, mesmo para depósitos aluviais. $\mathrm{O}$ detalhamento da metodologia pode ser encontrado no sítio eletrônico do laboratório responsável (http://www.datacao.com.br/).

Tabela 1. Dados das amostras dos depósitos fluviais amostrados para datação. Table 1. Data of the river deposits sampled for OSL dating.

\begin{tabular}{|c|c|c|c|}
\hline \multirow{2}{*}{ Amostra } & \multicolumn{3}{|c|}{ Localização do depósito } \\
\cline { 2 - 4 } & Vale & Coordenadas & Altitude (m) \\
\hline V01 & Alto Jequitibá/da Mata & $-19^{\circ} 29^{\prime} 53^{\prime \prime} ;-44^{\circ} 07^{\prime} 25^{\prime \prime}$ & 780 \\
\hline V02 & Baixo da Mata & $-19^{\circ} 43^{\prime} 26^{\prime \prime} ;-43^{\circ} 57^{\prime} 40^{\prime \prime}$ & 680 \\
\hline V04 & Médio Jequitibá & $-19^{\circ} 19^{\prime} 34^{\prime \prime} ;-44^{\circ} 09^{\prime} 10^{\prime \prime}$ & 690 \\
\hline V05 & Médio Jequitibá & $-19^{\circ} 19^{\prime} 05^{\prime \prime} ;-44^{\circ} 08^{\prime} 50^{\prime \prime}$ & 680 \\
\hline V06 & Baixo Jequitibá & $-19^{\circ} 18^{\prime} 44^{\prime \prime} ;-44^{\circ} 08^{\prime} 42^{\prime \prime}$ & 6 \\
\hline
\end{tabular}

\section{RESULTADOS}

Os depósitos fluviais identificados em porções superiores de colinas na área de estudo denotam processos de inversão de relevo. Foram identificados cerca de 100 registros, apresentando grande diversidade de características estratigráficas e sedimentares e graus de preservação variados. Entretanto, de modo genérico, os registros podem ser caracterizados por uma sucessão deposicional composta por cerca de $1 \mathrm{~m}$ de seixos arredondados de quartzo $(1-10 \mathrm{~cm})$ e de $5,5 \mathrm{~m}$ de sedimentos areno-argilosos, por vezes com pequenos seixos $(<3$ $\mathrm{cm}$ ) arredondados a sub-arredondados esparsos. Em alguns locais, as fácies superior e intermediária podem apresentar maior espessura, enquanto em outros podem ter sido totalmente removidas pelos processos erosivos ou não terem sido depositadas. Por vezes, as exposições analisadas desses depósitos têm forma acanalada, com cerca de $20 \mathrm{~m}$ de largura e, na porção mais espessa, mais de $6 \mathrm{~m}$ espessura (Fig. 3). A ocorrência de material cimentado (aparentemente por oxi-hidróxidos de ferro) foi localmente registrada no nível basal de seixos, como nas proximidades da cidade de Matozinhos (Fig. 4). Em alguns depósitos foram observados nódulos de ferro dispersos ao longo do perfil (petro-plintita), além de camadas contínuas de acumulações ferruginosas.

A datação de amostras coletadas forneceu idades condizentes com o Pleistoceno Tardio (Tab. 2). As idades abrangem o intervalo de 103.500 anos a 185.300 anos (Fig. 5). No entanto, considerando que a saturação do sinal LOE em grãos de quartzo pode ser alcançada com cerca de 150 mil anos ou menos (KocK et al. 2009; RixHON et al. 2017; BARTZ et al. 2018), é possível que a datação por LOE tenha alcançado apenas idades mínimas.

No vale do ribeirão da Mata, os sedimentos ocorrem a cerca de $800 \mathrm{~m}$ de altitude no interflúvio com o vale do ribeirão Jequitibá (Alto curso) e apresentam idade de $167.000 \pm 18.300$ anos. As cotas passam a $780 \mathrm{~m}$ no Baixo curso e a idade dos sedimentos a $121.700 \pm 16.400$ anos. Já no vale do ribeirão Jequitibá há um maior desnivelamento altimétrico entre os segmentos. Valores de $800 \mathrm{~m}$ de altitude e $167.000 \pm 18.300$ anos de idade no Alto curso passam a $690-680 \mathrm{~m}$ de altitude no MédioBaixo cursos, enquanto as idades passam a $164.000 \pm 29.900$ e $157.400 \pm 20.200$ anos. Já no Baixo curso, os sedimentos datados também estão na cota de $680 \mathrm{~m}$ e possuem idade de $115.100 \pm 11.600$ anos. A dinâmica e as taxas de encaixamento de cada curso d'água foram diferenciadas ao longo do tempo, resultando em compartimentos morfológicos e altimétricos distintos. Portanto, não há como comparar diretamente a relação entre cotas e idades dos sedimentos entre os dois vales. O ribeirão da Mata não apresentou incisão muito pronunciada entre os segmentos, resultando em um desnivelamento pouco significativo (diferença de somente $20 \mathrm{~m}$ entre o Alto e o Baixo curso). Já o ribeirão Jequitibá apresenta desnivelamento bem maior $(120 \mathrm{~m})$ entre o Alto e o Médio cursos, demonstrando uma dinâmica de encaixamento mais pronunciado entre esses segmentos. Estas diferenças entre os vales não encontra explicação no quadro litológico, pois a bacia do ribeirão da Mata é marcada por predomínio das friáveis rochas do Complexo Belo Horizonte na margem direita (granitos, gnaisses e migmatitos intemperizados) e das rochas da Formação Sete Lagoas (Grupo Bambuí) na margem esquerda (filitos, calcáreos e dolomitos). Já a bacia do ribeirão Jequitibá apresenta predomínio de rochas pelíticas da Formação Santa Helena (Grupo Bambuí), principalmente siltitos e folhelhos, e pouca ocorrência das rochas do Complexo Belo Horizonte (Fig. 6).

Os espessos registros deposicionais fluviais e os amplos vales dos ribeirões Jequitibá e da Mata não são proporcionais à área relativamente pequena 

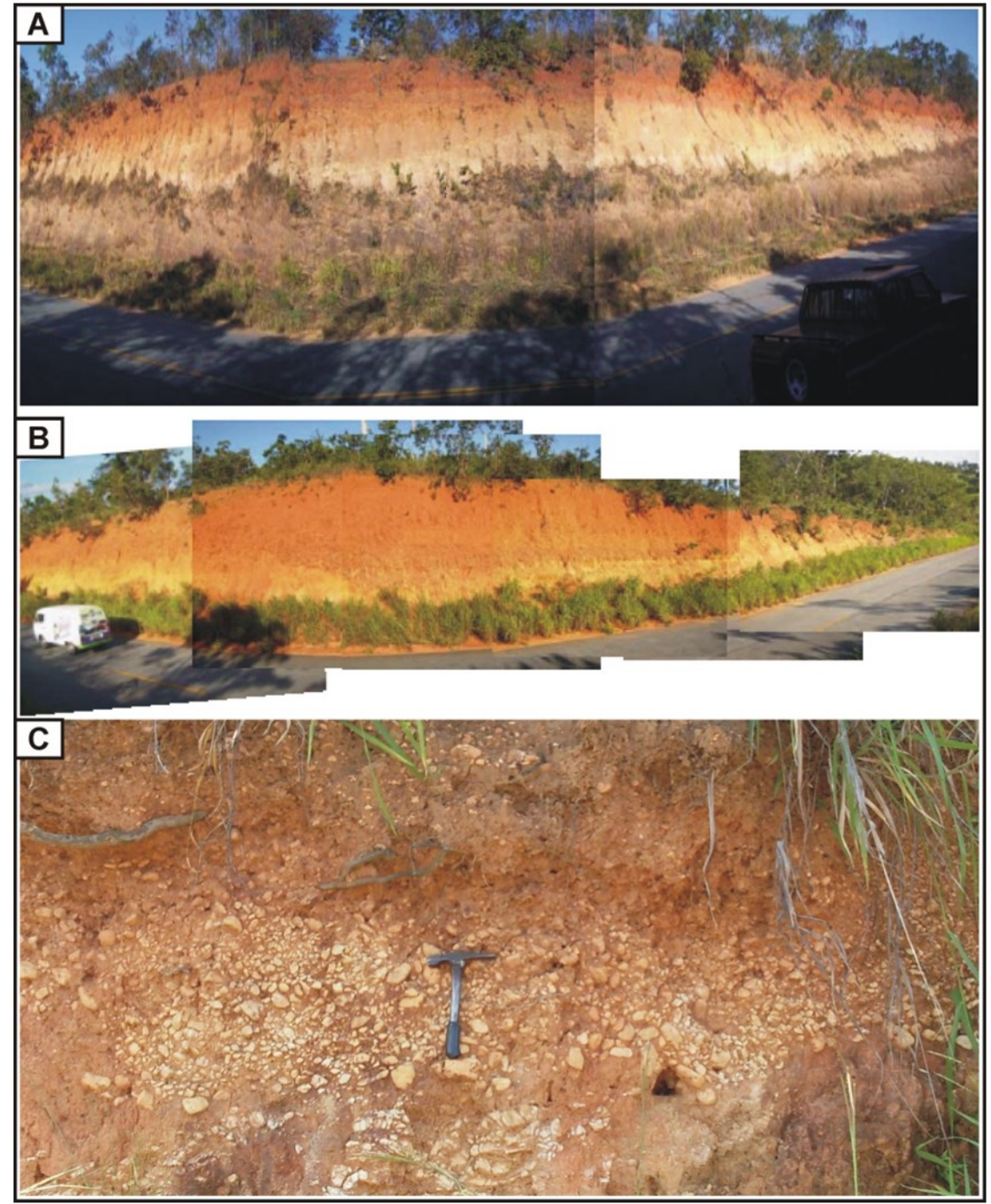

Fig. 3: Depósitos no vale do ribeirão Jequitibá com forma acanalada preservada (A e B) e detalhe para os clastos basais de um dos depósitos no paleovale (C).

Fig. 3: Deposits in the Jequitibá Ribeirão Valley, with preserved channeled shape, (A and B) and detail for the basal clasts of one of the paleovalley deposits (C).

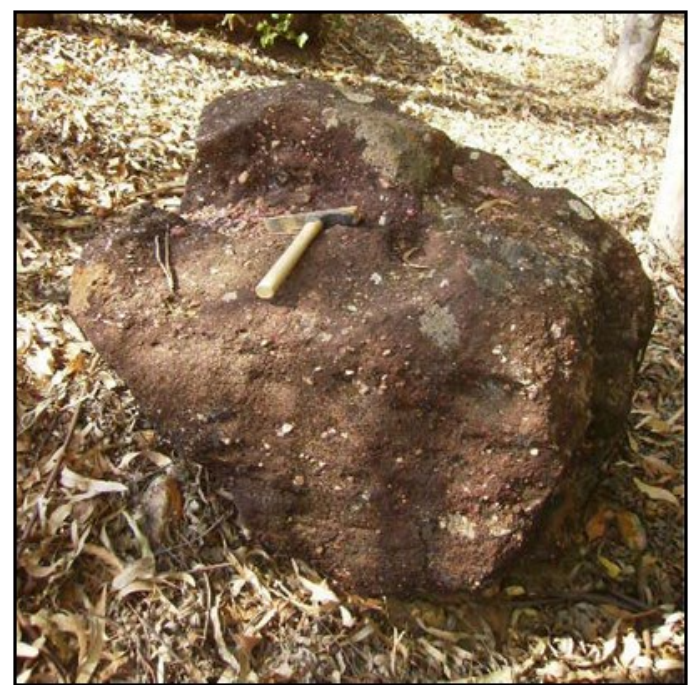

Fig. 4: Blocos residuais de sedimentos fluviais cimentados por oxi-hidróxidos de ferro, agregando seixos e matriz em uma massa compacta.

Fig. 4: Residual blocks of iron-cemented river sediments, aggregating pebbles and matrix in a compact mass. 
Tabela 2: Resultados das datações das amostras de sedimentos por LOE.

Table 2: Results of the OSL dating of sediment (quartz) samples.

\begin{tabular}{|c|c|c|c|c|c|c|}
\hline Amostra & $\begin{array}{c}\text { Th } \\
(\mathbf{p p m})\end{array}$ & $\begin{array}{c}\mathbf{U} \\
\mathbf{p p m})\end{array}$ & $\begin{array}{c}\mathbf{K} \\
\mathbf{( \% )}\end{array}$ & $\begin{array}{c}\text { Dose Anual } \\
(\boldsymbol{\mu G} \mathbf{G} / \mathbf{a n o})\end{array}$ & $\begin{array}{c}\text { Dose } \\
\text { Acumulada } \\
(\mathbf{G y})\end{array}$ & $\begin{array}{c}\text { Idade } \\
(\mathbf{a n o s})\end{array}$ \\
\hline $\mathrm{V} 01$ & $11,528 \pm 0,415$ & $3,630 \pm 0,315$ & $0,074 \pm 0,011$ & $2.077 \pm 123$ & 346,94 & $167.000 \pm 18.300$ \\
\hline V02 & $9,012 \pm 0,324$ & $3,105 \pm 0,388$ & $0,294 \pm 0,043$ & $1.979 \pm 168$ & 240,85 & $121.700 \pm 16.400$ \\
\hline V04 & $8,833 \pm 0,318$ & $2,760 \pm 0,104$ & $1,062 \pm 0,154$ & $2.663 \pm 208$ & 419,12 & $157.400 \pm 20.200$ \\
\hline V05 & $9,870 \pm 0,355$ & $3,191 \pm 0,730$ & $1,378 \pm 0,200$ & $3.176 \pm 420$ & 520,80 & $164.000 \pm 29.900$ \\
\hline V06 & $10,561 \pm 0,380$ & $2,838 \pm 0,025$ & $0,537 \pm 0,078$ & $2.275 \pm 115$ & 261,76 & $115.100 \pm 11.600$ \\
\hline
\end{tabular}

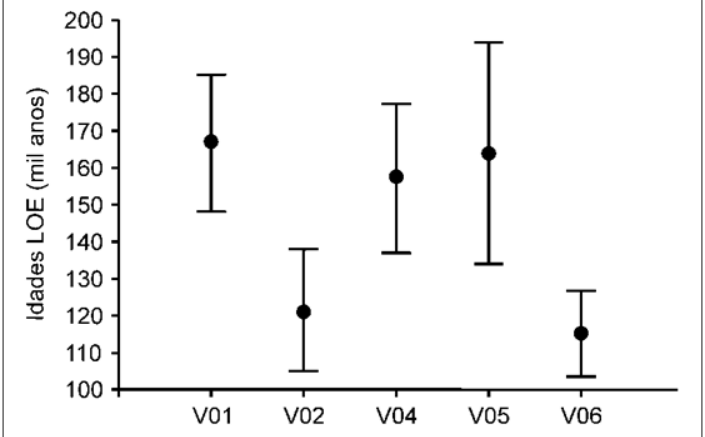

de suas bacias (624 e $787 \mathrm{~km}^{2}$, respectivamente). Essas características contribuem para a interpretação desses registros como pertencentes a um paleovale do Rio das Velhas, abandonado durante $\mathrm{o}$ Quaternário Tardio, conforme indicam as datações por LOE (Fig.6). Destaca-se que o Ribeirão da Mata é o único na região que drena em direção contrária ao Rio das Velhas. Isso ocorreria justamente pelo aproveitamento, por parte deste ribeirão, de um vale esculpido e posteriormente abandonado pelo Rio das Velhas. A organização de uma drenagem em sentido contrário ou muito oblíquo ao gradiente regional é um forte indício de controle tectônico (SCHUmm et al. 2000; Keller \& PinTer 2002; BoOth-Rea et al. 2004). Dado que o escudo brasileiro não experimentou glaciações no Quaternário, o substrato rochoso, as antigas estruturas e a tectônica são os principais fatores controladores da evolução do relevo (Hasui 1990; SAADI 1991). Os registros do paleovale atualmente encontrados nas cotas mais elevadas, em posição de interflúvios, podem denotar, neste sentido, as consequências de mudanças do nível de base regional e capturas fluviais. Estes processos levariam à migração acelerada do paleocanal do Rio das Velhas e ao abandono do paleovale do ribeirão Jequitibá. Além disso, os modernos ribeirões da Mata e Jequitibá apresentam reduzidas capacidade e competência de transporte, o que não condiz com as dimensões e o grau de arredondamento dos seixos que formam os registros deposicionais situados nas porções superiores de seus vales fluviais.

A abundância de acumulações ferruginosas em alguns depósitos também demandaria um significativo suprimento de ferro para os eixos de drenagem. Na bacia do Médio Rio das Velhas, onde se iniciam e se encerram os afluentes destacados, as
Fig. 5: Distribuição gráfica dos intervalos temporais das amostras datadas por LOE.

Fig. 5: Graphical distribution of age intervals of samples dated using OSL.

rochas pelíticas e carbonáticas do Grupo Bambuí não representam a fonte mais provável desse suprimento de ferro. Tal suprimento é, no entanto, condizente com o contexto geológico do Quadrilátero Ferrífero (Alto Rio das Velhas), onde afloram expressivas formações ferríferas bandadas que sustentam os principais topos das serras. $\mathrm{O}$ seu intemperismo levou à formação de couraças ferruginosas nos topos e, devido à exportação de ferro nesse processo, também nos fundos de vale (BARRos et al. 2016).

No compartimento cárstico situado no Médio vale do Rio das Velhas, Piló (1998) estudou a unidade morfológica denominada de Depressão Macacos-Baú, localizada na porção central do Carste de Lagoa Santa e, ao definir as principais etapas da morfodinâmica regional, o autor verificou a existência de desnível de $210 \mathrm{~m}$ entre o planalto residual e a atual calha fluvial, com entalhamento iniciado a 1,9 Ma. Como registros da morfodinâmica posterior ao início do entalhe, foram encontrados sedimentos depositados no interior de cavernas da região e datados em torno de 240 ka e 8 ka (PILó et al. 2005), quando o Rio das Velhas já teria a sua calha posicionada próxima do traçado atual ( $\sim 650 \mathrm{~m}$ de altitude). Reforça-se assim, que o modelado cárstico nessa região evolui através de um conjunto de interrelações entre o endocarste e o exocarste no Quaternário Superior, com importante papel do Rio das Velhas enquanto nível de base dinâmico, devido às várias fases de dissecação.

Em relação às idades obtidas por $\mathrm{LOE}$, os valores, ainda que considerados mínimos, são sempre superiores aos encontrados na bacia do Alto Rio das Velhas, no domínio do Quadrilátero Ferrífero. Sendo esta uma área de relevo mais serrano, haveria condições menos favoráveis para a 


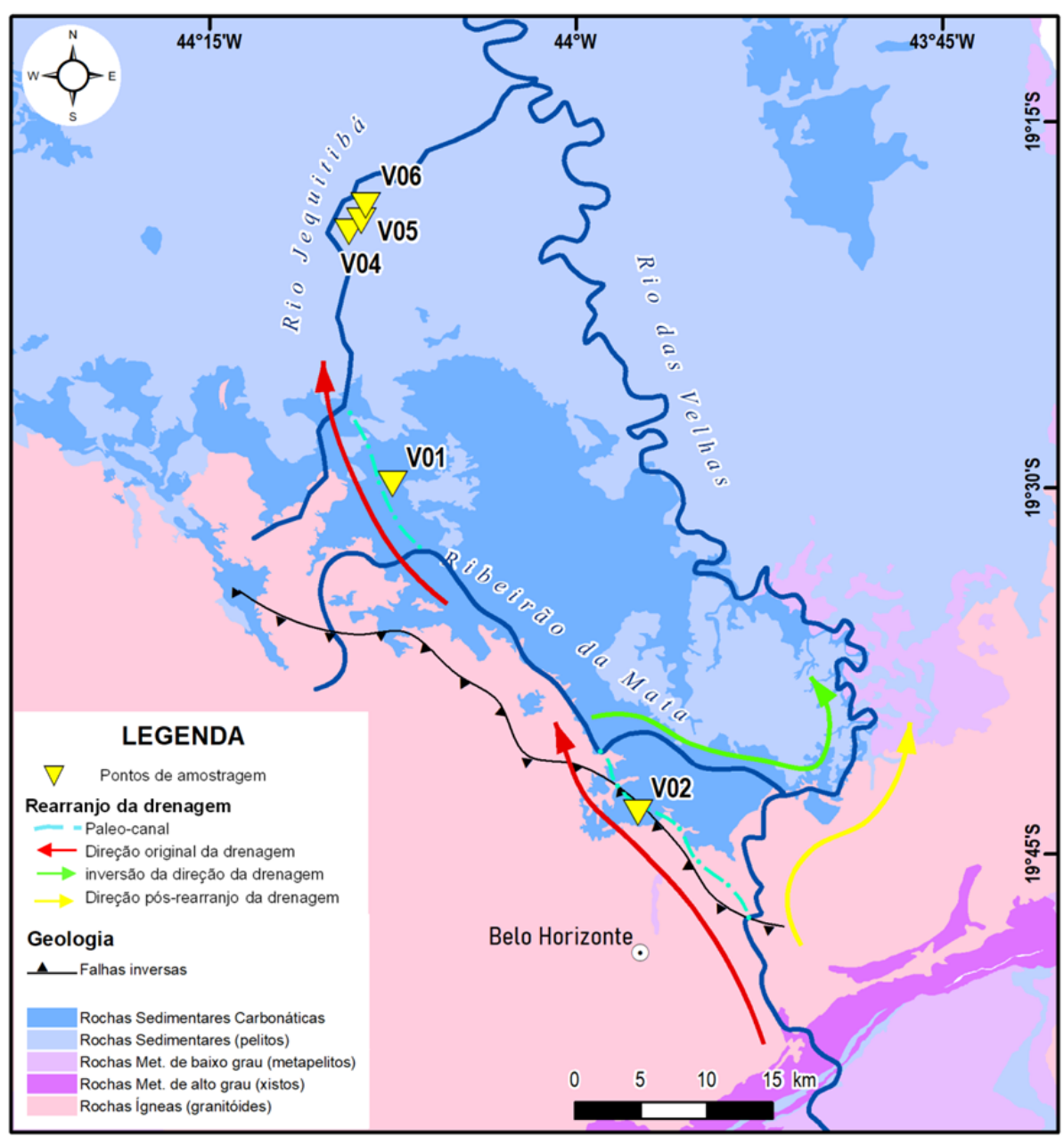

Fig. 6: Reconstituição do paleovale do Médio Rio das Velhas. Fig. 6: Reconstitution of the middle Velhas River paleovalley.

preservação de registros deposicionais fluviais mais antigos. Na região, os níveis deposicionais fluviais identificados foram datados entre 84-1 mil anos por LOE em grãos de quartzo (BARROS \& MAGALHÃES Jr. 2018b). Esses níveis são, em sua maioria, dos tipos escalonado e pareado e, portanto, configuramse como importantes marcadores dos ritmos da dissecação fluvial quaternária regional. Destaca-se o encaixamento de alguns cursos d'água ainda no Holoceno Superior. As datações permitem a associação de diferentes níveis fluviais com oscilações climáticas, que deixaram como registros couraças ferruginosas desenvolvidas sob um clima mais seco/frio que o atual, bem como o embutimento de planícies de inundação em níveis mais antigos, desenvolvidos durante o último máximo glacial.

Considerando as demais bacias que drenam o Quadrilátero Ferrífero, as idades no Médio Rio das Velhas ainda são superiores às encontradas na bacia do Rio Paraopeba (também afluente do Rio São Francisco) e na bacia do Alto Rio Doce. Na primeira, as idades variam entre 45-8 mil anos, sendo a de maior valor associada a um nível fluvial situado a mais de $60 \mathrm{~m}$ acima da drenagem atual, o que assinala a intensidade da dissecação fluvial na área no Quaternário Tardio (BARRos \& MAGALHÃES JR. 2018b). No Alto Rio Doce, as idades variam entre 139-1 mil anos, sendo a mais antiga associada a um nível fluvial situado a mais de $50 \mathrm{~m}$ acima da drenagem atual (BARROS \& MAGALHÃES JR. 2019). A diferença no poder de dissecação dessas bacias no contexto do Quadrilátero Ferrífero pode estar associada à formação cíclica de espessas couraças ferruginosas na bacia do Alto Rio Doce (BARRos et al. 2016).

Também na bacia do Médio Rio das Velhas, porém no contexto serrano da Serra do Espinhaço Meridional, Carvalho et al. (2018) mostram que esta também é uma área desfavorável à preservação de depósitos antigos. A maior idade obtida pelos autores é de $26.350( \pm 4.470)$ anos, no Córrego da Sepultura. A evolução dos vales nessa área pode ser dividida em duas fases (CARVALHO et al., 2018): i) a 
mais antiga, que compreende o final do Pleistoceno e o início do Holoceno, provavelmente foi marcada pela instabilidade neotectônica, expressa em uma dinâmica de blocos mais intensa, permitindo a instalação de eventos erosivo-deposicionais distintos em cada vale; ii) a mais recente, representada pelos últimos 2.000 anos, foi marcada pela menor movimentação de blocos no interior da Serra do Espinhaço Meridional, o que pode ter permitido a estabilização do nível de base regional e a regularização de grande parte dos perfis longitudinais dos cursos fluviais.

\section{CONSIDERAÇÕES FINAIS}

Os eventos de reorganização da drenagem são elementos chave para o entendimento da evolução do relevo no Cenozoico. Em Minas Gerais, o centro-leste do Cráton São Francisco é drenado pela bacia hidrográfica do Rio das Velhas, um dos maiores afluentes do Rio São Francisco. Investigações de registros sedimentares fluviais na bacia do Médio Rio das Velhas descrevem a ocorrência de depósitos em cotas superiores às até então conhecidas nos trechos de montante. Entretanto, em razão de suas dimensões e características sedimentares, os depósitos encontrados em vales de afluentes do Rio das Velhas (ribeirões da Mata e Jequitibá) se mostraram incompatíveis com seu contexto atual, sugerindo sua formação por uma paleodrenagem de maior capacidade e competência.

A descontextualização de um conjunto de depósitos fluviais em cotas superiores e topos de colinas e a existência de anomalias na organização da rede de drenagem e na composição dos depósitos sedimentares nesse trecho seriam resultantes da mudança do traçado do canal principal do Rio das Velhas. Dentre os indícios desse processo, destacam-se a organização do Ribeirão da Mata (afluente) em direção contrária à do Rio das Velhas; a dimensão incompatível dos depósitos encontrados nos vales dos afluentes, inclusive, próximo das cabeceiras; a formação de couraças ferruginosas em alguns depósitos, sugerindo um fornecimento abundante de ferro quando da formação dos registros analisados.

As datações por LOE revelam idades no intervalo entre $115.100 \pm 11.600$ anos e $167.000 \pm$ 18.300 anos. Em geral, essas idades são superiores às obtidas para depósitos de níveis fluviais nos trechos de montante (região do Quadrilátero Ferrífero) e em bacias afluentes do médio curso (na Serra do Espinhaço Meridional), demonstrando melhores condições de desenvolvimento e preservação desses registros no ambiente cárstico do médio curso. Entretanto, é possível que a datação por LOE tenha alcançado apenas idades mínimas, demandando análises baseadas em técnicas complementares em trabalhos futuros.

\section{REFERÊNCIAS}

Alvares, C.A.; Stape, J.L.; Sentelhas, P.C.; Moraes GonCALVES, J.L.; SparoveK, G. 2013. «Köppen's climate classification map for Brazil». Meteorologische Zeitschrift , 22 (6): 711-728.

Bacellar, L.A.P. Coelho Netto, A.L. \& Lacerda, W.A. 2005. Controlling factors of gullying in the Maracujá Catchment, Southeastern Brazil. Earth Surface Processes and Landforms, 30 : 1369-1385.

BARROS, L.F.P. \& MAGALHÃES JR., A.P. 2018a. Reconstituição de eventos geomorfológicos no Quadrilátero Ferrífero/ MG a partir de registros deposicionais fluviais: a bacia do Rio Paraopeba. Quaternary and Environmental Geosciences, 9(2): 36-48.

Barros, L.F.P. \& Magalhães JR., A.P. 2018b. Morfogênese no Quadrilátero Ferrífero/MG no Quaternário Superior: processos fluviais e condicionantes paleoambientais na bacia do Rio das Velhas. Revista Brasileira de Geomorfologia, 19(4) : 547-565.

Barros, L.F.P. \& Magalhães JR., A.P. 2019. O papel da bacia do Rio Doce na configuração geomorfológica do Quadrilátero Ferrífero/MG. Boletim de Geografia, 37(1) : 145-167.

Barros, L.F.P. \& Magalhães JR., A.P. 2012. Registros deposicionais do Quaternário Tardio no vale do ribeirão Sardinha, Quadrilátero Ferrífero/MG. In: SIMPÓSIO NACIONAL DE GEOMORFOLOGIA 9, Rio de Janeiro. Anais... Rio de Janeiro, 2012.

Barros, L.F.P.; Oliveira, F.S. \& MagalhÃes JR., A.P. 2016 Implicações geomorfológicas de couraças em nívei fluviais pleistocênicos no Quadrilátero Ferrífero/MG. In SIMPOSIO NACIONAL DE GEOMORFOLOGIA, 11, Maringá. Anais... Maringá, 2016

Barros, L.F.P.; Lavarini, C.; Lima, L.S. \& Magalhães JR., A.P. 2011. Síntese dos cenários paleobioclimáticos do Quaternário Tardio em Minas Gerais/Sudeste do Brasil. Sociedade \& natureza, 23(3) : 371-386.

Bartz, M.; Rixhon, G.; Duval, M.; KIng, G.E.; Posada, C.A.; Pares, J.M. \& BRÜCKNER, H. 2018. Successful combination of electron spin resonance, luminescence and palaeomagnetic dating methods allows reconstruction of the Pleistocene evolution of the lower Moulouya river (NE Morocco). Quaternary science reviews, $185: 153-171$.

Bishop, P. 1995. Drainage rearrangement by river capture beheading and diversion. Progress in Physical Geography, 19(4) : 449-473.

Benvenuti, M.; Bonini, M.; Moratti, G.; Ricci, M. \& TANINI, C. 2008. Tectonic and climatic controls on historical landscape modifications: The avulsion of the lower CecinaRiver (Tuscany, central Italy). Geomorphology, 100 : 269-284.

Booth-Rea, G., Azañón, J.-M.; A., Azor, A. \& GarciaDuENAS, V. 2004. Influence of strike slip fault segmentation on drainage evolution and topography. A case study: the Palomares Fault Zone (southeastern Betics, Spain). Journal of Structural Geology, 26(9) : 1615-1632.

Camargos, L.M.M. (coord.). Plano diretor de recursos hídricos da bacia hidrográfica do rio das Velhas. resumo executivo dezembro 2004. 2005. Instituto Mineiro de Gestão das Águas, Comitê da Bacia Hidrográfica do Rio das Velhas, $228 \mathrm{p}$

Costa, M.T. \& Grossi SAD, J.H. 1987. A Série Bambuí em Minas Gerais. In: SIMPÓSIO DE GEOLOGIA DE MINAS GERAIS, 4, Belo Horizonte. Anais... Belo Horizonte, 1987. 
Dumont, J.F.; Santana, E.; Valdez, F.; Tihay, J.P.; Usselmann, P.; Iturralde, D. \& Navarette, E. 2006. Fan beheading and drainage diversion as evidence of a 3200-2800 BP earthquake event in the Esmeraldas-Tumaco seismic zone: A case study for the effects of great subduction earthquakes. Geomorphology, $74: 100-123$.

HASUI, Y. 1990. Neotectônica e tectônica ressurgente no Brasil. In: WORKSHOP SOBRE NEOTECTONICA E SEDIMENTAÇÃO CONTINENTAL CENOZÓICA NO SE BRASIL, 1. Boletim da Sociedade Brasileira de Geologia-Núcleo Minas Gerais, 11, 1-32.

Jain, M.; Murray, A.S. \& Botter-Jensen, L. 2004. Optically stimulated luminescence dating: How significant is incomplete light exposure in fluvial environments? Quaternaire, 15 : 143-157.

JAMES, L.A. 1995. Diversion of the upper Bear River: Glacial diffluence and Quatemary erosion, Sierra Nevada, California. Geomorphology, 14 : 131-148

Keller, E.A. \& Pinter, N. 2002. Active tectonics: Earthquakes, Uplift and Landscape. Prentice Hall, Upper Saddle River, 206 p.

KING, L. 1956. A geomorfologia do Brasil oriental. Revista Brasileira de Geografia, 18(2) : 147-265.

Kock, S.; Kramers, J. D.; Preusser, F. \& Wetzel, A. 2009. Dating of Late Pleistocene terrace deposits of the River Rhine using Uranium series and luminescence methods: Potential and limitations. Quaternary Geochronology, 4(5) : 363-373.

Lana, C.E. \& Castro, P.T.A. 2010. Variabilidade morfológica em níveis de base do rio Maracujá (Quadrilátero Ferrífero MG): influências litológicas, estruturais e de reativações cenozóicas. Revista Brasileira de Geomorfologia, $11: 21-30$.

Magalhães JR, A.P. \& SAadi, A. 1994. Ritmos da dinâmica fluvial Neo-Cenozóica controlados por soerguimento regional e falhamento: o vale do rio das Velhas na Região de Belo Horizonte, Minas Gerais, Brasil. Geonomos, 2(1) : 42-54.

Magalhães Jr., A.P.; Barros, L.F.P.; RaPoso, A.A. \& CHEREM, L.F.S. 2012. Dinâmica fluvial quaternária do Rio Maracujá, Quadrilátero Ferrífero (MG). Revista Brasileira de Geomorfologia 13(1) : 3-14.

Magalhães Jr, A.P.; Cherem, L.F.S.; Barros, L.F.P. \& SAnTOS, G.B. 2011. OSL dating of sediments from a mountainous river in southeastern Brazil: Late Cenozoic tectonic and climatic implications. Geomorphology, 132 : 187-194.

MAther, A.E. 2000. Adjustment of a drainage network to capture induced base-level change: an example from the SorbasBasin, SE Spain. Geomorphology, 34 : 271289.

Miall, A.D. 1999. Principles of sedimentary basin analysis. New York: third edition: Springer-Verlag Inc., 1999. 616p.

Parizzi, M.G.; Salgado-Labouriau, M.L. \& Kholer, H.C. 1998. Genesis and environmental history of Lagoa Santa, southeastern Brazil. The Holocene, 8 : 311-321.

PILó, L.B. 1998. Morfologia cárstica e materiais constituintes: Dinâmica e evolução da Depressão Poligonal Macacos-Baú - Carste de Lagoa Santa Minas Gerais. 269p. (Tese de Doutorado) Departamento de Geografia da Faculdade de Filosofia, Letras e Ciências Humanas da Universidade de São Paulo.

Piló, L.B.; Auler, A.S.; Neves, W.A.; Wang, X.; Cheng, H. \& EDWARDS, R.L. 2005. Geochronology, sedi- ment provenance and fossil emplacement at Sumidouro Cave, a classic Late Pleistocene/Early Holocene Paleoanthropological site in Eastern Brazil. Geoarchaeology, 20(8) : 751-764.

Pinto, R.C. \& Magalhães JR., A.P. 2009. Eventos deposicionais cenozóicos no médio vale do Rio das Velhas: paleoníveis deposicionais e dinâmica atual. In: SIMPÓSIO NACIONAL DE GEOGRAFIA FÍSICA APLICADA, 13, Viçosa, 2009. Anais.. Viçosa: v. 1. p. 560-575.

Pinto, R.C. \& Magalhães JR., A.P. 2006. Interpretação e Reconstituição Sedimentar de Paleocanal no Vale do Córrego do Chaves - Sete Lagoas/MG. In: SIMPÓSIO NACIONAL DE GEOMORFOLOGIA, 6, Goiânia, 2006. Anais... Goiânia: v. 1. p. 58-58.

Raposo, A.A.; Oliveira, L.F.; Magalhães JR, A.P. \& CHEREM, L.F.S. 2008. Níveis e sequências deposicionais do vale do ribeirão do Mango, Quadrilátero Ferrífero/MG. In SIMPÓSIO NACIONAL DE GEOMORFOLOGIA, 7, Belo Horizonte, 2008. Anais... Belo Horizonte: v. 1, p. $110-120$.

Rixhon, G.; Briant, R.M.; Cordier, S.; Duval, M.; JoNESE, A. \& SCHOLZ, D. 2017. Revealing the pace of river landscape evolution during the Quaternary: recent developments in numerical dating methods. Quaternary Science Reviews, 166 : 91-113.

SAADI, A. 1991. Ensaio sobre a morfotectônica de Minas Gerais: tensões intra-placa, descontinuidades crustais e morfogênese. Tese (Concurso de Professor Titular do IGC/UFMG). Instituto de Geociências, Universidade Federal de Minas Gerias, Belo Horizonte.

SAADI, A. 1995. A geomorfologia da Serra do Espinhaço em Minas Gerais e de suas margens. Geonomos, 3(1) : 41-63.

Schumm, S.A.; Dumont, J.F. \& Holbrook, J.M. 2000. Active Tectonics and Alluvial Rivers. Cambridge University Press, Cambridge, 276 p.

SILVA, T.M. 2009. Superfícies geomórficas do planalto sudeste brasileiro: revisão teórica-conceitual GeoUERJ, 3(20) : 1-22.

Trompette, R.R.; Uhlein, A.; Silva, M.E. \& Karmann, I. 1992. O Craton Brasiliano do São Francisco - uma revisão. Revista Brasileira de Geociências, 22(4) : 481-486.

UhleIn, A. \& PaIm, P.S.G. 1989. O Grupo Bambuí na Porção Sudeste da Bacia: Sistemas Deposicionais e Relação Estrutural com a Faixa Araçuaí (MG). SIMPÓSIO DE GEOLOGIA NÚCLEO MINAS GERAIS, 5, SIMPÓSIO DE GEOLOGIA NÚCLEO BRASÍLIA, 1, Belo Horizonte. Anais.. Belo Horizonte, 1989.

VALADÃO, R.C. 2009. Geodinâmica das superfícies de aplainamento, desnudação continental e tectônica ativa como condicionantes da megageomorfologia do Brasil Oriental. Revista Brasileira de Geomorfologia, 10(2) : 77-90.

VALADÃO, R.C. \& SILveIRA, J.S. 1992. Estratigrafia Quaternária e evolução do Relevo no Complexo do Bação, Dados Preliminares. Revista Escola de Minas, 45 : 85-87.

VARAJão, C.A.C. 1991. A questão da correlação das superfícies de erosão do Quadrilátero Ferrífero, Minas Gerais. Revista Brasileira de Geociências, 21(2) : 138-145. 